\title{
A Test of the Revenue Equivalence Theorem using Field Experiments on eBay*
}

\author{
Tanjim Hossain \\ Princeton University
}

\author{
John Morgan \\ University of California at Berkeley
}

\begin{abstract}
We conducted 80 auctions on eBay. Forty of these auctions were for various popular music CDs while the remaining 40 auctions were for video games for Microsoft's Xbox gaming console. The revenue equivalence theorem states that any auction form having the same effective reserve price yields the same expected revenue. The effective reserve price on eBay consists of three components: the opening bid amount, the secret reserve amount, and the shipping and handling charge. We set no secret reserve price and varied the opening bid and the shipping and handling charge to keep the overall reserve level fixed. When the effective reserve was $\$ 4$, auctions with a low opening bid and high shipping charges attracted more bidders, earlier bidding, and yielded higher revenue than those with a high opening bid and low shipping charges. The same results holds only for Xbox games under the $\$ 8$ effective reserve. Unlike the other treatments, where the reserve represents less than $30 \%$ of the retail price of the item, for CDs, the $\$ 8$ effective reserve represents over $50 \%$ of the retail price of the item. In this treatment, we find no systematic difference in the number of bidders attracted to the auction or revenues as a function of how the effective reserve is allocated between opening bid and shipping charges. We show that these results can be accounted for by bounded-rational bidding behavior.
\end{abstract}

JEL Classification Numbers: C93, D44, L86.

Keywords: Internet auctions, field experiments, test of revenue equivalence, behavioral economics, loss aversion.

${ }^{*}$ We thank Mike Baye, Richard Engelbrecht-Wiggans, Antonio Rangel, Ken Steiglitz, and Steve Tadelis for helpful comments. The second author also thanks Charles Thibeaux for his able research assistance in conducting earlier pilot experiments. The first author gratefully acknowledges the financial support of the Woodrow Wilson Foundation. The second author gratefully acknowledges the financial support of the National Science Foundation. Please direct all correspondence to John Morgan at morgan@haas.berkeley.edu. 


\section{Introduction}

Auction theory has widely been viewed as one of the most successful applications of information economics. Results from auction theory have guided the formulation and development of auctions for items ranging from oil leases to the telecommunications spectrum licenses. Auction theory has been applied to suggest alternative auction procedures ranging from treasury auctions (see Hortacsu, 2002) to auctions for logging rights (see, for instance, Paarsch, 1997). Auction theory results (see Bulow and Klemperer, 1996) have influenced SEC discussions on the merits of auctions versus negotiations in the sale of companies. Perhaps the most important finding in auction theory is the revenue equivalence theorem (Myerson, 1981; Riley and Samuelson, 1981). Roughly, this implies that different auction forms that award a single object to the same bidder and exclude the same set of bidders yield the same expected revenue to the seller. This paper reports the results of field experiments, conducted on eBay, to test revenue equivalence theorem and its ancillary predictions. While many of the predictions of auction theory are borne out in our experiments, we identify conditions where revenue equivalence systematically fails to hold in the data.

To test the revenue equivalence theorem, we conducted 80 auctions on eBay. Forty of these auctions were for various popular music CDs while the remaining 40 auctions were for video games for Microsoft's Xbox gaming console. Since these items are

readily available at retail stores, differential expertise among bidders about the value of the item would seem to play little role. Further, since these items tend to be of short-lived popularity, resale value is unlikely to be an important consideration either. Thus, it seems reasonable to suppose that private value considerations dominate bidding. All of these auctions were conducted on the online auction site eBay under 
their standard auction rules. The eBay rules are, in effect, an English auction run over a seven day period; thus, one cannot manipulate the auction form (first-price versus second-price, say) in testing the revenue equivalence theorem here. ${ }^{1}$ Instead, our experiments manipulate the structure of the reserve price. The revenue equivalence theorem states that any auction form having the same effective reserve price yields the same expected revenue. The effective reserve price on eBay consists of three components: the opening bid amount, the secret reserve amount, and the shipping and handling charge. The effective reserve on eBay is the shipping charge plus the larger of the opening bid and the secret reserve. In our experiments, we set no secret reserve price. We varied the opening bid and the shipping and handling charge to keep the overall reserve level fixed. Our main finding is that, when the effective reserve price is less than $30 \%$ of the retail price of the object, then, for a given effective reserve, a auctioneer earns greater revenue by setting a lower opening bid and a higher shipping charge. When the effective reserve is more than $50 \%$, our results are consistent with the revenue equivalence theorem.

Specifically, we auctioned 4 copies each of 10 popular music CDs and 10 Xbox games. Half of these auctions were run with a $\$ 4$ effective reserve and the other half with an $\$ 8$ effective reserve. For a given reserve amount, we auctioned off matched pairs of CDs where we varied the level of the opening bid and the shipping cost by $\$ 4$ while holding fixed the overall reserve level. When the effective reserve was $\$ 4$, auctions with a low (\$0.01) opening bid and high (\$3.99) shipping charges attracted more bidders, earlier bidding, and yielded higher revenue. We obtained the same results for Xbox games under the $\$ 8$ effective reserve. For CDs, the $\$ 8$ effective reserve represents over $50 \%$ of the retail price of the item. We find no systematic

\footnotetext{
1 The interested reader should see Roth and Ockenfels (2002) for additional details about the specifics of bidding on eBay.
} 
difference in the number of bidders attracted to the auction or revenues as a function of how the effective reserve is allocated between opening bid and shipping charges.

The nearest antecedent to our paper is Katkar and Lucking-Reiley (2000). They conducted auctions for Pokémon trading cards on eBay to test the equivalence between public and secret reserve prices. With secret reserve price, bidders can place bids below the reserve price while with public reserve price they cannot. This leads to higher bid activity and information transmission in secret reserve price auctions. Thus, for items like collectible trading cards that have a significant resale value, public and secret reserve prices provide different informational structures. Unlike them, we never use the secret reserve price feature of eBay in our auctions. Hence, our analysis is secure from issues about difference in information structures. Lucking-Reiley (1999, 2000) also conducted field experiments for collectible trading cards on Usenet. His experiments differ from ours in that he does not seek to directly test the revenue equivalence theorem. Instead, he varies the level of the reserve price and finds that the general predictions of auction theory are mainly borne out. In some treatments of our experiments, we also vary the level of the effective reserve price and find results consistent with auction theory as well as Lucking-Reiley. Our paper is somewhat related to List and Lucking-Reiley (2000), who examine whether the auction theory prediction of demand reduction in multiple unit uniform price auctions is observed in the data also using field experiments. To study this question, they run multiple unit uniform price and Vickrey auctions experiments at a sports memorabilia trade show where they auction off pairs of sports trading cards. Their results are broadly consistent with theory.

Also somewhat related are findings on the revenue equivalence theorem in laboratory experiments with induced values. One of the earliest such experiments is 
by Coppinger, Smith and Titus (1980). They examine revenue equivalence among four different auction forms - first-price, second-price, English, and Dutch. They find that the four forms fail to be revenue equivalent with the first-price and Dutch auctions outperforming the English and second-price auctions. The failure of the revenue equivalence between first and second price auctions has been widely observed (see, for instance Davis and Holt, 1993; and Kagel, 1995 for surveys of the literature). This failure is often attributed to considerations of risk-aversion-revenue equivalence between the two auction forms only holds under risk-neutrality. There has been considerable success in showing that adding risk aversion parameters rationalizes the data from first-price auctions (see, for instance, Holt and Sherman, 2000). Our study differs from this literature along two dimensions. First, our test of the revenue equivalence theorem is run solely under an English auction format. Therefore, unlike comparisons of first and second price auctions, the theoretical result does not depend on risk preferences. Second, our experiments are conducted using field experiments on the Internet's leading auction outlet (eBay). Our "subjects" are familiar with the rules of bidding in this setting and the objects being auctioned are real rather than abstract as in the case of the induced value structure used in laboratory settings. Finally, unlike laboratory experiments, our subjects are not aware that they are participating in an experiment.

To summarize, our paper makes two important contributions relative to the existing literature. We are the first to test the revenue equivalence theorem using field experiments using goods where expertise and resale value are not key considerations; that is, where the private values model has its best chance of succeeding. Our test itself is also novel: We are the first to test the predictions of the revenue equivalence theorem by varying, in a way that naturally occurs on eBay, the structure of the 
effective reserve price without changing the structure of information received by the bidders.

The remainder of the paper proceeds as follows: In section 2, we detail the experimental methodology. In section 3, we present the results of the experiments. In section 4, we consider a number of possible explanations for our findings. Finally, section 5 concludes.

\section{Procedures}

In designing the experiment, we chose a setting as close to the independent private values model as possible. In particular, we wanted to auction goods where multiple units of the same good are identical, where potential bidders have unit demand, where expertise in valuing the object is unlikely to be a significant factor, where purchasing for the purpose of eventual resale is unlikely to be a dominant motive, and where markets are thick enough that our auctions were unlikely to have a marked effect on market prices for these goods overall. This rules out collectibles, where obtaining identical units might prove difficult and where resale is a serious consideration. It also rules out obscurer items, where the market is likely to be thin. Instead, we focused on personal entertainment goods: music CDs and Xbox games. These items are of similar physical dimensions (both are CDs), and since they are readily available in retail markets, it is easy to obtain multiple units of the same good that are absolutely identical. Further, since there is a well-developed retail market and since the popularity of these items tends to be fleeting, there is little expertise in evaluating the purchase price for the items nor is resale likely to be an important consideration. Finally, since bidders are presumably buying the music CD to listen to it or the game CD to play 
it, there is little value for a single buyer to obtain multiple copies of the same CD; hence, we think the unit demand assumption is likely to be satisfied for these goods. One possible case where unit demand can be violated is if many bidders were dealers of products. However, participants in these categories on eBay are seldom dealers and, moreover, all winners were individual consumers.

Having chosen the category of goods we thought were likely to conform most closely to the assumptions needed for revenue equivalence, we did a survey of eBay sales in each of these markets to select items that are currently popular sellers within each category. By choosing relatively popular CDs, we would expect smaller variance in the sale price from random fluctuations in demand for the good. Further, we hoped that the thickness of the market would disguise the fact that we are running a field experiment and that, consequently, bidders might behave differently than they would of they were unaware that they were participating in an experiment.

A number of studies have found the existence of reputation effects on sales price for eBay auctions (see, for instance, Resnick and Zeckhauser, 2002). To control for this effect, we generated unique seller identities for each of the goods we sold. Each of these seller identities had a zero feedback rating and a "sunglasses" icon associated with it indicating that the seller was newly registered on eBay.

For each type of good (music CDs and Xbox games) we ran four treatments. The first two treatments were constructed as follows: In treatment A, we set an opening bid of $\$ 4$ and set the shipping and handling cost of the item at $\$ 0$. Thus, all bidders valuing the item at $\$ 4$ or less should, according to the theory, not choose to bid on the item. The remaining bidders should simply bid their value for the item up to a maximum equal to the retail price including shipping costs. In treatment $\mathrm{B}$, we set an opening bid of $\$ 0.01$ and a shipping cost of $\$ 3.99$. Again, bidders valuing the item 
less than $\$ 4$ should choose not to bid on the item while it is a dominant strategy for the remaining bidders to bid up to their value less the $\$ 3.99$ shipping cost. If bidders have private values, these two treatments are predicted to be revenue equivalent. We will refer to treatments A and B collectively as "low reserve price" treatments.

The second set of two treatments were as follows: In treatment $\mathrm{C}$, the opening bid was set at $\$ 6$ and the shipping cost at $\$ 2$. Thus, bidders with valuations below $\$ 8$ should not bid for the item while the remainder should bid their value less $\$ 2$. Finally, treatment D set the opening bid at $\$ 2$ and the shipping and handling cost at $\$ 6$. Here, it is a dominant strategy for bidders with values less than $\$ 8$ not to participate in the auction and for those whose values are above $\$ 8$ to bid their value less the $\$ 6$ shipping cost. If bidders have private values, treatments $\mathrm{C}$ and $\mathrm{D}$ are predicted to be revenue equivalent. We will refer to treatments $\mathrm{C}$ and $\mathrm{D}$ collectively as "high reserve price" treatments.

Finally, theory predicts that the number of bidders should be lower under the high reserve price treatments than under the low reserve price treatments. Likewise, the probability that the good goes unsold should be higher under the high reserve price treatments than under the low reserve price treatments.

For all treatments, we used an identical description of the good and the stipulated the exact method of shipping (USPS first-class). The exact wording used in each of the auctions is given in the Appendix. To control for the possibility that local bidders might assume that shipping and handling charges might be avoided by picking up the item in person, we responded to all bidder queries along these lines that the shipping and handling charge was non-negotiable and that in-person pickup was not possible. Upon receipt of payment, all items were shipped to the winning bidder exactly as described. 
Our first round of experiments consisted of auctioning four copies of each of the 10 music CDs. Each of these CDs was purchased new (and sealed) from Amazon.com. In every case, we used the standard seven day closing rules on eBay, varying only the opening bid and the shipping and handling amounts as described above. We ran the low reserve price treatments for auctions scheduled to end on 11/19/2001 and 11/20/2001 (a Monday and a Tuesday, respectively). For the auctions scheduled to end on Monday, we flipped a coin for each CD to determine whether we would run treatment A or treatment B. On a heads flip, we ran treatment A, otherwise we ran treatment B. The following day, we posted auctions for the same $10 \mathrm{CDs}$ using the opposite treatment. Thus, for each CD, treatments A and B occur (in random order) on consecutive days. The reason for adopting this procedure is that we would expect there to be little difference in demand for auctions for a given CD that are 24 hours apart. Further, if there is a systematic Monday versus Tuesday effect on revenues, our randomization should avoid confounding this with a treatment effect. The following week, we performed an identical procedure for the high reserve price treatments. All of the auctions ended between eight and ten p.m. eastern standard time.

Our second round of experiments, which consisted of auctioning four copies of each of 10 Xbox games, occurred in March 2002. Each of these games was purchased new and sealed from Amazon. We chose the timing of this round of experiments to avoid the Christmas holiday, when we expected demand might be different from other times of the year. We followed exactly the same procedures as with the music CDs. Table 1 and 2 present a summary of the results of these eighty auctions. 


\section{Results}

\subsection{Overview}

Table 1 presents a summary of the results from the music CD auctions. The retail prices for each of the CDs represent the cost to us from purchasing from Amazon, allocating the total shipping cost equally over all 40 music CDs. For the low reserve price treatments, all but one of the CDs auctioned was sold; whereas under the high reserve price treatments, 5 out of the 20 CDs went unsold. This is broadly consistent with the prediction that higher reserve prices are more likely to lead to failures to sell. Conditional on being sold, the average final sale price (including shipping) for the low reserve price treatments was $\$ 9.30$. Under the high reserve price treatments, the final price conditional on a sale was $\$ 12.21$. This too is consistent with theoretical predictions that prices conditional on a sale occurring are higher under a higher reserve price. Finally, sale prices on eBay tend to be well below the retail price. The average price we paid was $\$ 14.82$ per CD; thus, winning bidders in our auctions received "bargains" compared to buying at Amazon.

The second thing to note is that, in contrast to winning bidders in these auctions did not disproportionately consist of so-called "snipers," bidders who bid in the last few minutes (or seconds) of the closing time of the auction. Out of 36 CDs that were sold, the winning bid came in the last five minutes in only 5 auctions. Only 7 of the 36 auctions had any bid occurring in the last 5 minutes of the closing time. This is in contrast to other researchers (see, for instance, Roth and Ockenfels, 2002 and Bajari and Hortacsu, 2002), who have found evidence of extensive sniping on eBay. Bajari and Hortacsu argue that sniping is an optimal strategy for goods where expertise in assessing the eventual resale is important. As we stressed above, our goods are 
commodity items where present consumption is likely to be the dominant motive and where expertise seems secondary; that is, where something close to the private values model seems appropriate. The absence of much sniping is not inconsistent with this premise.

Next, we check for the presence of "day of the week" effects in the data. Under the null hypothesis that there are no systematic differences between Mondays and Tuesdays, the revenue ranking for each pair of CDs should be the outcome of a fair coin flip. We find that for 7 out of 18 music CDs, higher revenue was obtained on Tuesday compared to Monday; thus we do not find evidence of a systematic day of the week effect. ${ }^{2}$

Table 2 presents a summary of the results from the Xbox auctions. Again, the retail prices for each of these items represents the cost to us of purchasing from Amazon allocating the total shipping cost equally over all 40 Xbox games. In all treatments, every Xbox game was sold. The average final sale price (including shipping) for the low reserve price treatments was $\$ 37.47$. Under the high reserve price treatments, the final price conditional on a sale was $\$ 39.01$. This is consistent with the theoretical prediction that prices conditional on a sale occurring are higher under a higher reserve price. As with the music CDs, sale prices on eBay tend to be below the retail price. The average price we paid was $\$ 51.07$ per Xbox game; thus, winning bidders in our auctions received "bargains" paying about $72 \%$ of the cost at Amazon.

We observed more sniping in Xbox games. Thirteen out of 40 auctions were won by snipers bidding in the last 5 minutes of the close of the auction, and 15 out of 40 auctions saw some sniping. Still, the majority of these auctions were won by nonsnipers. Finally, we check for "day of the week" effects in this data. We find that

\footnotetext{
${ }^{2}$ In the high reserve price treatment, the CDs "Oops!... I did it again" and "Automatic for the People" did not sell under either treatment; hence there is no revenue ordering for these items.
} 
out for 9 out of 20 pairs of Xbox auctions, higher revenue was obtained on Monday compared to Tuesday, which again leads us to conclude that there is little evidence of a systematic day of the week effect in our data.

We now turn to more specific tests of the theory, which we group into two broad categories: tests of revenue rankings and tests of number of bidder effects.

\subsection{Revenues}

Table 3 compares revenues under the low reserve treatments. Notice for music CDs, the average revenue under treatment B is $\$ 10.14$ compared to only $\$ 7.54$ in treatment A. Of course, part of this difference is accounted for by the fact that one of the CDs under treatment A did not sell. If we exclude this CD from the averages, the average under treatment B still exceeds that under treatment A by $\$ 1.79$, or about $21 \%$ of the price CDs sold for under treatment A. For Xbox games, average revenues under treatment B still exceed those under treatment A, but by a smaller margin, only $\$ 0.71$ (or $2 \%$ of the revenues under treatment A). Taken together, however, this suggests that there might be systematic revenue differences between the two treatments. More formally, we can test the null hypothesis of revenue equality against the one-sided alternative that B outperforms A using a binomial test. This essentially involves a count of the number of auctions in which treatment B yielded higher revenues than did treatment A. In 9 out of 10 matched pairs of auctions for music CDs, this is the case. In 7 out of 10 matched pairs of auctions for Xbox games treatment B outperforms $\mathrm{A}$. Thus, for 16 out of 20 matched pairs of auctions with low reserve prices, we find that treatment B outperforms treatment A. The p-value of the one-sided binomial test is 0.005, which implies that we can reject the null hypothesis implied by the revenue equivalence theorem at the $99.5 \%$ level. 
Table 4 compares revenues under the high reserve treatments. Here, one sees a distinct difference in the ranking of average revenues between CDs and Xbox games. Excluding the two CDs that went unsold under both treatments, the average revenues under treatment $\mathrm{C}$ are $\$ 11.63$ compared to $\$ 11.26$ under treatment D. Thus, here we do not find that increasing shipping costs and reducing the opening bid one-for-one is revenue enhancing. However, this difference in revenues is reversed if we exclude "Unplugged in New York"; that is, if we only look at revenues arising when the same CD sold under both treatments. Here, we find that treatment D yields average revenue of $\$ 12.87$ compared to $\$ 12.15$ under treatment C. Regardless, the presence of the treatment effect on revenues is tenuous at best. One can use a binomial test to formalize this. In 4 matched pairs of auctions, treatment D had higher revenue than treatment $\mathrm{C}$, in another 4 matched pairs, this revenue ranking is reversed. Finally, in 2 auctions, the CD did not sell under either treatment, so the revenues are the same. Clearly, one fails to reject the null hypothesis of revenue equivalence at any level for these data; that is, a treatment effect is absent.

For Xbox games, the situation more closely resembles that in Table 3. Average revenues under treatment $\mathrm{D}$ are higher by $\$ 4.11$ compared to treatment $\mathrm{C}$. This is an $11 \%$ difference in revenues. Further, in 10 out of 10 matched pairs of auctions, treatment D yields higher revenues than treatment C. Clearly, we can reject the null hypothesis of revenue equivalence in favor of the one-sided alternative at any significance level.

The key feature that the low reserve price treatments and the high reserve price treatment with Xbox games share is that the reserve is less than $27 \%$ of the retail price. In contrast, for CDs under the high reserve price treatments, the reserve represents $53 \%$ of the retail price. Thus, the data suggest that the theoretical prediction 
of revenue equivalence fails systematically for relatively low reserve prices but not for relatively high reserve prices. In section 4 , we will return to this idea and offer some ex post theoretical rationales drawn from behavioral economics to try to explain this difference.

Table 5 examines the effect of raising the total reserve price across treatments. Recall that treatment $\mathrm{C}$ and $\mathrm{D}$ are constructed by adding $\$ 2$ to the opening bid and $\$ 2$ to the shipping cost to treatments A and B, respectively. Having already established that pooling treatments $\mathrm{A}$ and $\mathrm{B}$ is not justified, we study revenues under $\mathrm{C}$ versus A (Table 5) and D versus B (Table 6) to get at reserve price effects.

Looking at CDs in table 5, we earlier observed that the probability of not selling the item was higher under treatment C (2 items unsold) compared to treatment A (1 item unsold). Further, theory predicts that, conditional on a sale, revenues should be higher under treatment $\mathrm{C}$ compared to $\mathrm{A}$. As the table shows, conditional on the sale of the item, average revenues under $\mathrm{C}$ are $\$ 11.63$ versus $\$ 8.61$ under treatment $\mathrm{A}$. Further, in 7 of 8 auctions where the CDs were sold under both treatments, revenue was higher under treatment $\mathrm{C}$ than treatment A. Again, using a binomial test, we obtain a p-value of 0.035 or the one-sided alternative hypothesis predicted by the theory compared to the null hypothesis of no treatment effect.

Theory does less well when we consider Xbox games. Here, all items sold under both treatments, so there was no observable difference in the probability of a good going unsold. Further, the average revenues under the high reserve treatment, treatment C, are lower than under treatment A. Finally, there is no systematic difference in the revenues for a given game across treatments. Treatment $\mathrm{C}$ yields higher revenues than A for 4 of 10 matched pairs, whereas A yields higher revenues than $\mathrm{C}$ for 5 out of 10 matched pairs. Revenues are exactly equal for the game NHL 2002. Thus, 
one cannot reject the null hypothesis of no treatment effect at conventional levels for this data.

Table 6 compares revenues under treatments B and D. Looking at CDs, again we find a higher probability that the item goes unsold with a high reserve price. This happens three times under treatment $\mathrm{D}$ and never under treatment B. Conditional on the item being sold, average revenues are higher $(\$ 12.87)$ under treatment D than under treatment B $(\$ 11.21)$. Further, conditional on the item being sold, treatment D yields higher revenues in 6 out of 7 matched pairs. Results are quite similar for Xbox games. Average revenues are higher for treatment D compared to treatment B, and, indeed, in 10 out of 10 matched pairs, D yields higher revenues than B. Pooling the results of tables 5 and 6 , the bulk of the evidence is consistent with what the theory predicts. Lucking-Reiley (2000) obtains similar findings in terms of variation in the reserve price in his field experiments for collectible trading cards.

\subsection{Bidders}

Table 7 presents an analysis of how bidding behavior differed in each of the treatments for the music CD auctions. First, notice that in comparing treatment B to treatment A, treatment B averages about 0.6 more bidders per auction. Comparing treatments $\mathrm{C}$ and D, treatment D averages only 0.2 more bidders than treatment C; thus, whatever effect shipping the reserve from the opening bid to shipping and handling cost has in inducing bidder participation, it is attenuated in the high reserve treatments. Table 8 presents a similar analysis for Xbox games. Here there are an average of 8.8 bidders from Xbox games under treatment B, whereas there are only 7.8 under treatment A, which is consistent with what we saw for music CDs. Comparing treatments $\mathrm{C}$ and $\mathrm{D}$ for Xbox games, we find that an average of 1.6 more bidders bids under treatment 


\section{D than under treatment $\mathrm{C}$.}

To test more formally for a treatment effect on the number of bidders, we use a Wilcoxon signed-ranks test to test the null hypothesis of no treatment effect against the one-sided alternative suggested by the summary data. Pooling the matched pairs of both $\mathrm{CD}$ and Xbox auctions and testing the null hypothesis that the number of bidders in treatments $\mathrm{A}$ and $\mathrm{B}$ are equal, we obtain a test statistic of $z=1.514$, which is not significant at $5 \%$ level. Likewise, pooling the matched pairs of auctions and testing the null hypothesis that treatments $\mathrm{C}$ and $\mathrm{D}$ are equal, we obtain a test statistic of $z=1.971$, which is significant at conventional levels. Thus, we find evidence of a treatment effect in the number of bidders which is similar to what we observed in revenues.

Next, we turn to changes in the level of the reserve price. Recall that increases in the level of the overall reserve price are predicted to decrease the number of bidders by excluding those with values between the two different reserve price levels. Comparing treatments $\mathrm{A}$ and $\mathrm{C}$ (or B and D) in Table 7, one sees evidence of this effect. Compared to treatment $\mathrm{A}$, the average number of bidders under treatment $\mathrm{C}$ falls by 1.1 bidders. Likewise, compared to treatment B, the average number of bidders under treatment D is lower by 1.5 bidders. Qualitatively similar results do not occur for Xbox games as shown in table 8. compared to treatment A, the average number of bidders under treatment $\mathrm{C}$ increases by 0.6 bidders. Similarly, compared to treatment $\mathrm{B}$, the average number of bidders in treatment $\mathrm{D}$ increases by 1.3 bidders. The evidence is, at best, mixed concerning the theoretical prediction that higher reserve prices should reduce the number of active bidders participating in the auction.

The theory also predicts that auctions attracting a larger number of bidders will have higher expected revenues. To study this question, we compare the revenues 
under treatments $\mathrm{A}$ and $\mathrm{B}$ for each matched pair of CDs and ask how often the auction with the higher revenues attracted (weakly) more bidders. The evidence is consistent with the theory, in 9 out of 10 auctions, the auction with the higher number of bidders obtained the higher revenue. Similarly for Xbox games comparing treatments $\mathrm{A}$ versus B. In this case, in 8 out of 10 auctions, the treatment attracting the higher number of bidders obtained the higher revenue. Comparing treatments $\mathrm{C}$ versus D, one obtains similar results: In 6 out of 8 cases, the CD auction with the higher number of bidders obtained the higher revenue, while in 9 out of 10 cases, the Xbox auction with the higher number of bidders obtained the higher revenue. Thus, it seems that the transmission mechanism for the revenue ranking we obtained above is that auctions with lower opening bid amounts succeed in attracting more bidders than those with higher opening bids, holding the total reserve price constant.

The analysis in Table 9 suggests a more nuanced explanation, auctions with lower opening bid amounts attract earlier bidding and this, in turn, leads to higher revenues. As Table 9 shows, there is strong correlation between receiving the earlier first bid and obtaining higher revenue. Out of 38 matched pairs of auctions, in 29 of these the treatment receiving the earlier bid obtained the higher revenue. Thus, it seems that, holding the overall reserve price fixed, auctions with lower opening bid amounts attract earlier bidders, and this in turn leads to greater overall bidding interest in the item, which ultimately results in higher revenues.

Returning to Tables 7 and 8, we explore some additional details of bidding behavior. In these tables, we divide bidders into certain types based on their bidding patterns. The types we consider are:

Nibblers - These are bidders whose initial bid does no make them the high bidder and who then increase their subsequently bids at small increments; that is, they 
"nibble" at the second highest price.

Returners - These are bidders who had a bid that was the high bid, were subsequently displaced, and who returned to make a subsequent bid.

Both-These are bidders who were both a nibbler and a returner.

Snipers - These are bidders who make a bid in the last hour of the auction.

Returning Snipers - These are bidders who make a bid in the last hour of the auction, but who had previously placed a bid earlier in the auction.

Because eBay permits proxy bidding, that is, a bidder is free to make a bid up to his true value and then rely on is "bidding bot" to increase his bid up to that level as needed, it is an optimal strategy under the usual private value models in auction theory to simply submit a single bid, equal to private value. Indeed, if there is some opportunity cost to submitting multiple bids, a bidder would be strictly better off, under the standard model, to bid once and stop. As the table shows, however, there is a significant amount of multiple bidding in our auctions; indeed, about one-third of all bidders submit multiple bids. Now, one possible explanation for multiple bidding is that bidders bid early as a way to create a "bookmark" for an auction in which they are interested, thereby reducing the cost of late bidding. That is, most of the multiple bidding should be in the form of returning snipers. As the table shows, however, there is little evidence of this type of behavior in auctions for music CDs. Out of 40 auctions of CDs, we observe returning snipers exactly three times. They are more sniping by returners in Xbox games auctions. We observe 15 returning snipers in 12 out of 40 auctions. 


\section{Discussion}

While the RET predicts that two auctions for identical items with the same total reserve price should yield the same expected revenue, we find evidence that for auctions on eBay, lowering the opening bid and increasing shipping charges while holding the total reserve price constant raises the revenue of the seller. It seems to do this by attracting earlier and more bidders to the auction. In this section, we discuss a number of possible theoretical models that might rationalize the observed results.

\section{Loss Aversion and mental accounting}

Two essential characteristics of a value function to evaluate outcomes of risky prospects proposed by Kahneman and Tversky (1979) and Tversky and Kahneman (1991) are reference-dependence and loss aversion. Reference-dependence suggests that an agent defines gains and losses with respect to a reference point. Loss aversion hypothesize that negative utility received from a loss is greater in size than utility received from a gain of the same amount.

Further, Kahneman and Tversky (1984) and Thaler (1985) postulate that consumers retain separate metal accounts for different aspects of a purchase decision. Experimental evidence show that a decision maker makes different choices when presented with relevant data in different accounting formats. One plausible way this might happen in our setting is that bidders have separate accounts for shipping and for the good itself.

Combining these observations allows us one way to rationalize our findings as follows: Suppose bidders have separate mental accounts for shipping and the good itself with less emphasis on shipping. Then the treatment with higher shipping costs will generate higher expected revenue than the treatment with lower shipping cost. 
However, if bidders are loss-averse with respect to some reference level, then a very high shipping cost may lead to revenue equivalence and revenue performance can even be reversed.

We offer a simple model to operationalize this intuition. Suppose a consumer with total valuation of $v$ for some object has a reference level of $v_{s}$ for shipping charges. When she pays a price of $p$ and shipping cost of $s$ in winning an auction, her utility is:

$$
U(v, p, s)=\gamma u\left(v-v_{s}-p\right)+\alpha u\left(v_{s}-s\right) .
$$

Here $\alpha$ is smaller than $\gamma$ and for simplicity we assume $\gamma=1$. If the utility function $u($.$) demonstrates loss aversion then u(x) \geq u(-x)$ and $u^{-1}(x) \geq-u^{-1}(-x)$ for all positive $x$. For a fixed $s$, the buyer resets her maximum bid to $p^{*}$ where

$$
\begin{aligned}
& p^{*}=v-v_{s}-u^{-1}\left(-\alpha u\left(v_{s}-s\right)\right) \\
\text { and } \quad & p^{*} \leq v-v_{s}+u^{-1}\left(\alpha u\left(v_{s}-s\right)\right) .
\end{aligned}
$$

Since the agent is loss-averse, if $\alpha u\left(v_{s}-s\right)>u\left(s-v_{s}\right)$ for all $s>v_{s}$ then a bidder's bid will be increasing in $s$ for $s \leq v_{s}$ and decreasing in $s$ for $s>v_{s}$.

Hence, we can have a situation where

$$
\begin{aligned}
& u\left(v-v_{s}-p_{1}+k\right)+\alpha u\left(v_{s}-s_{1}\right) \geq u\left(v-v_{s}-p_{1}\right)+\alpha u\left(v_{s}-s_{1}+k\right) \text { but } \\
& u\left(v-v_{s}-p_{2}+k\right)+\alpha u\left(v_{s}-s_{2}\right) \leq u\left(v-v_{s}-p_{2}\right)+\alpha u\left(v_{s}-s_{2}+k\right) .
\end{aligned}
$$

For example, suppose $s_{1}=v_{s}, s_{2}=2 v_{s}, p_{2}=p_{1}-v_{s}, \alpha>.5, \frac{\alpha}{1-\alpha} v_{s} \geq k \geq v_{s}$ and

$$
u(x)=\left\{\begin{array}{c}
2 x \text { for } x<0 \\
x \text { for } x \geq 0
\end{array} .\right.
$$


Then plugging in these values, we obtain:

$$
\begin{aligned}
& v-v_{s}-p_{1}+k \geq v-v_{s}-p_{1}+\alpha k \text { and } \\
& v-p_{1}+k-2 \alpha v_{s} \leq v-p_{1}+\alpha\left(k-v_{s}\right) . \\
& \text { That is, } U\left(v, p_{1}-k, s_{1}\right) \geq U\left(v, p_{1}, s_{1}-k\right) \text { but } \\
& U\left(v, p_{2}-k, s_{2}\right) \leq U\left(v, p_{2}, s_{2}-k\right) .
\end{aligned}
$$

This means that a bidder of valuation $v$ bids higher in the auction with higher shipping cost in the first case and she bids higher in the auction with lower shipping cost in the second (high reserve price) case.

This hypothesis is testable. Let us assume that $v_{s}$ is the same for all agents for some good. If shipping charges are smaller than $v_{s}$ for treatment $\mathrm{C}$ but not treatment $\mathrm{D}$, treatment $\mathrm{C}$ may generate revenue higher than or equivalent to that of treatment D. On the other hand, if shipping charges are smaller than $v_{s}$ for all treatments $\mathrm{A}$, through D then there will not be loss aversion effects for any treatment. Hence, treatments $\mathrm{B}$ and $\mathrm{D}$ will outperform treatments $\mathrm{A}$ and $\mathrm{C}$ respectively. It is worth mentioning that on eBay, average shipping and handling fee for new music CDs is between $\$ 3$ and $\$ 4$ and for new Xbox games is between $\$ 5$ and $\$ 6$. Thus, our findings from the music CD and Xbox games experiment are consistent with this explanation.

\section{Salience}

The eBay display makes the current second highest bid much more prominent than the shipping cost. Suppose that a fraction of the potential bidders simply ignore shipping costs when making their bids. In this case, it is still a weakly dominant strategy for each bidder to bid up to his or her expected surplus. Thus, when shipping is zero, the expected price is simply the second highest valuation for the object. When 
shipping is positive, a fraction of bidders discount by the amount of the shipping, whereas bidders who ignore shipping continue to bid up to their values for the object, this leads to a distribution of bids that first-order stochastically dominates the no shipping cost environment and one obtains the revenue ranking we observe.

It seems plausible that the salience of shipping costs depends on two things, the ratio of shipping cost to the total cost of the item and the level of shipping cost itself. We postulate that the fraction of bidders ignoring shipping cost is given by $\lambda(\rho, s)$ where $\rho$ is the ratio of shipping cost to the retail price of the good and $s$ is the level of shipping cost. We would expect that $\frac{\partial \lambda}{\partial \rho}<0$ and $\frac{\partial \lambda}{\partial s}<0$.

Under these assumptions, we obtain the ancillary prediction that revenue differences, for a given total shipping cost, revenue differences should be greater for Xbox games than for CDs (since $\rho$ is smaller for Xbox) and revenue differences should be reduced for higher shipping treatments than for lower shipping treatments. First we test that the revenue difference (between the high shipping cost and low shipping cost treatments) for low reserve price treatments will be greater than that for high reserve price treatments. This is a difference-in-differences $((B-A)-(D-C))$ measure and we use the standard one-sided t-statistic for testing the null hypothesis that the mean of a normal population is zero. Here the difference-in-differences in revenue for a given music CD is considered as one observation. Next we test that the revenue difference for Xbox games are greater than that for music CDs. We test this for low reserve price and high reserve price treatments separately. We treat the revenue difference $(B-A$ or $D-C)$ for CDs and Xbox games as two different population samples whose means we would like to compare. Since these two populations may not have the same variance, we use the one-sided Smith-Satterthwaite test for comparing the means of two processes with different variances. The degree of freedom (df) for 
this test involves both the number of observations in each sample and the sample variances.

The results of these tests, presented in table 10, are somewhat consistent with the salience explanation. Specifically, we reject (at 95\% confidence level) the two alternative hypotheses that:

i) for low reserve price treatments revenue difference for Xbox games is larger than music CDs and

ii) for Xbox games revenue difference is higher for the low reserve price treatment. While we can reject (at 95\% confidence level) the null hypotheses in favor of the one-sided alternatives implied by the salience model that:

i) for high reserve price treatments revenue difference for Xbox games is larger than music CDs and

ii) for music CDs revenue difference is higher for the low reserve price treatment.

Finally, we offer several alternative explanations that we model less formally.

\section{Suspicious Bidders}

Another possibility is that some bidders have a preference for a more familiar auction format than a less familiar one. ${ }^{3}$ While free shipping is sometimes offered on eBay auctions, it is less common than auctions with positive shipping costs, so it may be less familiar to bidders. Further, bidders may view the familiarity of the auction as a signal of the quality of the seller. For instance, bidders may infer from the low shipping charge that the seller is a low quality seller. This might mean that they expect the speed of shipping to be slower (although we described the shipping method using identical language in both types of auctions) or that there is a greater possibility of not receiving the good at all (although we restricted payment to credit

\footnotetext{
${ }^{3}$ We thank Michael Baye for suggesting this possibility.
} 
cards so that bidders are mostly insulated against this problem). For these reasons, it might be that fewer bidders choose to participate in less familiar auctions and that this accounts for the revenue ranking. This explanation seems less plausible in explaining the same revenue ranking for Xbox games under treatments $\mathrm{C}$ and $\mathrm{D}$. There seems little a priori reason to suppose that bidders are less familiar with an auction with a $\$ 2$ shipping charge than a $\$ 6$ shipping charge. Further, if they are, then one should see a similar revenue ranking for music CDs under these two treatments, but this is inconsistent with the data.

There are, however, some reasons to doubt this explanation. First, many online retailers, such as Barnes and Noble and Amazon have gone to a free shipping policy for purchases about some modest amount. Indeed, the trend in online retail seems to be toward more free shipping. So how unfamiliar is free shipping to bidders? Second, field experiments by List and Lucking-Reiley (2000) found confirmation of many of the theory predictions in comparing the uniform price auction to a 2-unit Vickrey auction, which is a very unfamiliar auction format.

\section{Love of Winning}

Suppose that bidders obtain utility simply from winning the auction itself, in addition to their surpluses. In particular, suppose that the utility from winning is a decreasing function of the difference between the winning bid and the retail price of the object. In this case, since bidders are shading down bids for positive shipping treatments, the love of winning "bonus" is greater in when shipping is positive than when it is zero. This leads to a failure of the RET consistent with our findings. However, this do not explain the return of revenue equivalence in the high reserve price treatment for music CDs. Moreover, if love of winning is independent of price level or fully accounts for shipping costs, then revenue equivalence once again obtains. 


\section{Costly Search}

Another alternative explanation postulates that the cost of seach might account for our findings. ${ }^{4}$ Suppose that bidders use the following search strategy: Sort the prices for the desired item from lowest to highest then bid only on the low price item. In that case, since auctions run under treatments B and D have lower initial listed prices than those run under treatments $\mathrm{A}$ and $\mathrm{C}$, these auctions would be more likely to attract earlier bidders and this increase in bidders translates into higher revenue. While this explanation explains the revenue ranking and number of bidders we observe in the low reserve treatments for both types of products and in the high reserve treatment for Xbox games, it does not explain why revenue equivalence holds for the high reserve treatments in the CD auctions. Nor does it explain why Xbox games with high reserves attract more bidders than those with low reserves.

\section{Sequential Auctions}

The standard IPV model assumes a one-shot game for a single object. In reality, we conducted sequential English auctions for two identical goods. McAfee and Vincent (1993) analyze the case where two identical objects are auctioned sequentially in an IPV setting where bidders desire only a single object. ${ }^{5}$ Although they assume zero reserve price, their results hold for any reserve price in the support of bidder valuations for risk-neutral bidders. When the sequential auctions are English auctions, they show that while it remains a dominant strategy to bid sincerely in the

\footnotetext{
${ }^{4}$ We thank Richard Englebrecht-Wiggans for suggesting this possibility.

${ }^{5}$ In reality, we conducted sequential auctions for goods that were readily obtainable through conventional retail outlets as well as in other auctions. Moreover, for some music CDs and Xbox games we sold, there were other concurrent auctions selling brand new products. Furthermore, bidders had no way of knowing that there will not be another auctioneer selling shrink-wrapped disks the next day. Thus, it might make more sense to think of bidders as playing stationary longrun strategies, in which case there should be no difference in the bids in the two auctions and revenue equivalence should still hold. Our analysis show that bidders do not systematically bid higher in the auction ending later.
} 
second auction, it is no longer the case for the first auction. In that auction, bidders should bid up to their expected surplus conditional on not winning the first auction and bidding sincerely in the second. This model delivers a pair of testable predictions for risk-neutral bidders:

1. Bids in the first auction should be shaded downward compared to the second auction.

2. The expected revenue in the first auction should be the same as that in the second. The intuition for prediction 2 is that, since bidders are bidding to equalize expected surplus in the two auctions, hence revenue equivalence follows.

Prediction 1 does not seem to occur in the data. We do not find significant revenue difference between the first and the second auctions and thus prediction 2 holds in our data. However, that can be also explained by bidders playing stationary longrun strategies. Moreover, we do not find any systematic difference in the number of bidders between the first and the second auctions. This seems to suggest that bidders do not view these auctions as sequential auctions.

\section{Conclusions}

We have shown that when the effective reserve price is not a large fraction of the retail price of the item, the structure of the reserve price affects the number of bidders, the timing of bids, and, most importantly, the revenue derived from the auction. Setting a low opening bid and a high shipping and handling cost yields systematically higher

revenue than doing the reverse. When the effective reserve is more than $50 \%$ of the retail value of the item, we do not observe these systematic differences. We present two theories that attempt to ex post rationalize our findings. One theory suggests 
that bidders might be loss averse and maintain separate mental accounts for shipping charges and the price of the item itself. Under such a framework, we show that an apparently revenue-neutral variation in the structure of the effective reserve price can lead to revenue differences consistent with those we find. The second theory we consider has to do with the salience of shipping charges. Some fraction of bidders might simply overlook the shipping charge when making bids. We would expect that as the shipping charge becomes large relative to the final price of the item, fewer people will ignore it. This theory also leads to systematic variation in revenue as a function of the structure of the reserve price.

We can think of two main directions in which our results might affect future research. First, our results suggest that optimal auction design that ignores the behavioral element to the structure of reserve prices is likely to miss important tools for revenue maximization on the part of sellers. The revenue differences we find as a result of out "revenue-neutral" variation in the structure of the effective reserve price are on the order of $10 \%$. It seems clear that a theory of optimal auctions incorporating behavioral elements is warranted. Our results also suggest that one must be cautious about using structural estimation of field data to ascertain buyer valuations and then using these findings to suggest alternative auction forms. Our results suggest that even seemingly innocuous elements of the auction design, such as the structure of the effective reserve price, would affect bidder participation, the timing of bids, and ultimately, the revenues of the auction. Using structural estimation to identify bidder valuations under treatment A of our auctions would lead to different predictions for optimal reserve prices were one to do the same exercise under treatment B. 


\section{References}

[1] Bajari, P., and A. Hortacsu (2002): "Winner's Curse, Reserve Prices and Endogenous Entry: Empirical Insights from eBay Auctions," Working Paper, Stanford University.

[2] Bulow, J., and P. D. Klemperer (1996): "Auctions vs. Negotiations," American Economic Review, 86, 180-194.

[3] Coppinger, V. M., V. L. Smith, and J. A. Titus (1980): "Incentives and Behavior in English, Dutch and Sealed-Bid Auctions," Economic Enquiry, 18, 1-22.

[4] Davis, D. D., and C. A. Holt (1993): Experimental Economics, Princeton, Princeton University Press.

[5] Holt, C. A., and R. Sherman (2000): "Risk Aversion and Winner's Curse," Working Paper, University of Virginia.

[6] Hortacsu, A. (2002): "Bidding Behavior in Divisible Good Auctions: Theory and Evidence from the Turkish Treasury Auction Market," Working Paper, Stanford University.

[7] Kagel, J. H. (1995): "Auctions: A Survey of Experimental Research," Handbook of Experimental Economics, J. H. Kagel and A. E. Roth, editors, Princeton, Princeton University Press, 501-585.

[8] Kahneman, D., and A. Tversky (1979): "Prospect Theory: An Analysis of Decision Under Risk," Econometrica, 47, 263-291.

[9] Kahneman, D., and A. Tversky (1984): "Choices, Values, and Frames," American Psychologist, 39, 341-350. 
[10] Katkar, R., and D. Lucking-Reiley (2000): "Public Versus Secret Reserve Prices in eBay Auctions: Results from a Pokémon Field Experiment," Working Paper, Vanderbilt University.

[11] List, J. A., and D. Lucking-Reiley (2000): "Demand Reduction in Multi-Unit Auctions: Evidence from a Sportscard Field Experiment," American Economic Review, 90, 961-972.

[12] Lucking-Reiley, D. (1999): "Using Field Experiments to Test Equivalence Between Auction Formats: Magic on the Internet," American Economic Review, 89, 1063-1080.

[13] Lucking-Reiley, D. (2000): "Field Experiments on the Effects of Reserve Prices in Auctions: More Magic on the Internet," Working Paper, Vanderbilt University.

[14] McAfee, R. P., and D. R. Vincent (1993): "The Declining Price Anomaly," Journal of Economic Theory, 60, 191-212.

[15] Myerson, R. B. (1981): "Optimal Auction Design," Mathematics of Operation Research, 6, 58-73.

[16] Paarsch, H. J. (1997): "Deriving an Estimate of the Optimal Reserve Price: An Application to British Columbian Timber Sales," Journal of Econometrics, 78 , 333-357.

[17] Resnick, P., and R. Zeckhauser (2002): "Trust Among Strangers in Internet Transactions: Empirical Analysis of eBay's Reputation System.," The Economics of the Internet and E-Commerce, Advances in Applied Microeconomics, Vol. 11, Michael R. Baye, editor, Amsterdam, Elsevier Science, forthcoming. 
[18] Riley, J., and W. Samuelson (1981): "Optimal Auctions," American Economic Review, 71, 381-392.

[19] Roth, A. E., and A. Ockenfels (2002): "Last-Minute Bidding and the Rules for Ending Second-Price Auctions: Evidence from eBay and Amazon Auctions on the Internet," American Economic Review, 92, 1093-1103.

[20] Thaler, R. H. (1985): "Mental Accounting and Consumer Choice," Marketing Science, 4, 199-214.

[21] Tversky, A., and D. Kahneman (1991): "Loss Aversion in Riskless Choice: A Reference-Dependent Model," Quarterly Journal of Economics, 106, 1039-1061. 


\section{Appendix}

This section gives the exact wording used in placing our auctions on eBay.

\section{Auctions}

Title: $\{$ Name of CD here $\}$ - Brand New in Original Shrink Wrap

This superhit CD is brand new in original shrink wrap. The songs are:

$\{$ List of songs here. $\}$

I accept only Paypal or Billpoint payments.

Buyer pays shipping and handling charge of \{insert shipping charge here.\} I will ship via first-class mail.

I will ship to US and Canada only.

Happy Bidding.

For the free shipping treatment, this paragraph read:

There is no shipping and handling fee for this CD. I will ship via first-class mail.

I will ship to US and Canada only.

Happy Bidding.

\section{Xbox Auctions}

Title: BRAND NEW!!! \{Name of Xbox Game here\} XBOX GAME!!! *SEALED*

Text: This superhit game for Microsoft XBOX system is brand new and is in original shrink wrap.

I accept payment only by Paypal or money orders.

Buyer pays a fixed shipping and handling charge of \{insert shipping charge here\}, and I will deliver by USPS first-class mail as soon as the payment is received. Payment should be sent within 10 days of the end of the auction.

I will ship to US and Canada only. 


\section{Happy Bidding.}

For the free shipping treatment, this paragraph read:

There is no shipping and handling fee for this Xbox game. I will deliver by USPS

first-class mail as soon as the payment is received. Payment should be sent within 10 days of the end of the auction.

I will ship to US and Canada only.

Happy Bidding. 
Table 1. Overview of Music CD Auctions

Low Reserve Treatments:

\begin{tabular}{|c|c|c|c|c|c|c|c|c|c|c|c|c|}
\hline Total Reserve $=\$ 4$ & \multicolumn{6}{|c|}{ Auctions Starting on 11/12/2001 } & \multicolumn{6}{|c|}{ Auctions Starting on 11/13/2001 } \\
\hline CD & \begin{tabular}{|l|} 
Treatment \\
\end{tabular} & $\mathbf{R e}$ & venues & (\# bids, \# bidders) & high bid time & last bid time & Treatment & & evenues & (\# bids, \# bidders) & high bid time & last bid time \\
\hline Music & $A$ & $\$$ & 5.50 & $(4,2)$ & d7 h24 & same & $\mathrm{B}$ & $\$$ & 7.24 & $(6,4)$ & d7 h24 & last minutes \\
\hline Ooops! I Did it Again & $B$ & $\$$ & 7.74 & $(10,4)$ & d4 h24 & d7 h02 & $A$ & $\$$ & 6.50 & $(3,3)$ & d7 h19 & last minutes \\
\hline Serendipity & $A$ & $\$$ & 8.50 & $(5,4)$ & last minutes & same & B & $\$$ & 10.49 & $(8,4)$ & d6 h22 & same \\
\hline O Brother Where Art Thou? & $B$ & $\$$ & 11.99 & $(7,4)$ & d7 h18 & same & $A$ & $\$$ & 12.50 & $(7,7)$ & d7 h20 & same \\
\hline Greatest Hits - Tim McGraw & $B$ & $\$$ & 15.99 & $(12,8)$ & d4 h06 & d7 h24 & $A$ & $\$$ & 11.00 & $(11,8)$ & d7 h24 & same \\
\hline A Day Without Rain & $A$ & $\$$ & 13.50 & $(7,6)$ & d6 h23 & d7 h23 & B & $\$$ & 14.99 & $(9,6)$ & d7 h12 & d7 h21 \\
\hline Automatic for the People & $A$ & $\$$ & - & $(0,0)$ & - & - & B & $\$$ & 9.99 & $(5,3)$ & last minutes & same \\
\hline Everyday & $A$ & $\$$ & 7.28 & $(3,3)$ & d4 h23 & d6 h23 & B & $\$$ & 9.49 & $(9,7)$ & d7 h24 & same \\
\hline Joshua Tree & $A$ & $\$$ & 6.07 & $(3,3)$ & last minutes & same & B & $\$$ & 8.25 & $(6,3)$ & d7 h22 & same \\
\hline Unplugged in New York & B & $\$$ & 5.24 & $(5,2)$ & d7 h18 & same & $A$ & $\$$ & 4.50 & $(3,3)$ & d7 h17 & same \\
\hline
\end{tabular}

High Reserve Treatments:

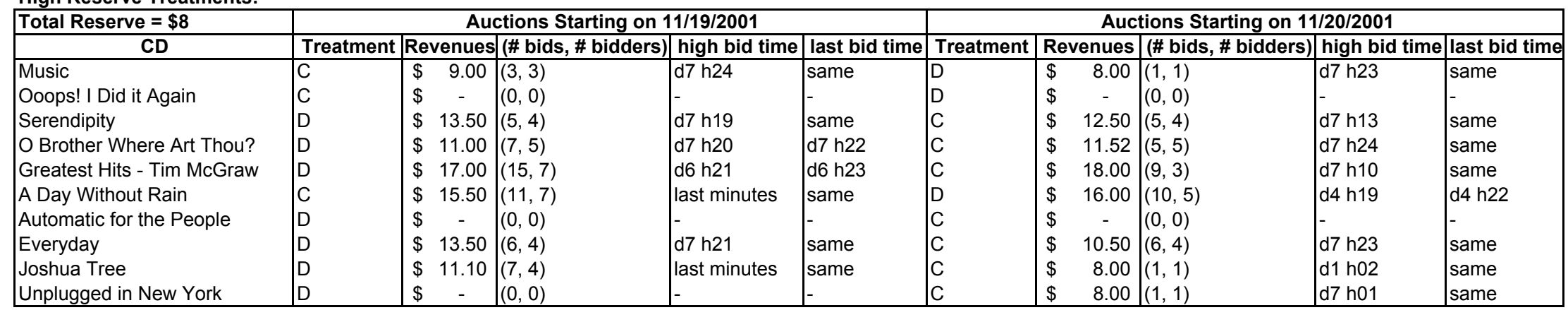

\begin{tabular}{|l|c|}
\hline (Opening Bid, Shipping Cost) & Treatment \\
\hline$(\$ 4,0)$ & $\mathrm{A}$ \\
$(\$ 0.01, \$ 3.99)$ & $\mathrm{B}$ \\
$(\$ 6, \$ 2)$ & $\mathrm{C}$ \\
$(\$ 2, \$ 6)$ & $\mathrm{D}$ \\
\hline
\end{tabular}

Comments:

bidding time = day ( 1 to 7$)$, hour ( 1 to 24 )

"same" in the "last bid time" column means the last bid was the high bid

"last minutes" = bid in the last 5 minutes 
Table 2. Overview of Xbox Auctions

Low Reserve Treatments:

\begin{tabular}{|c|c|c|c|c|c|c|c|c|c|c|}
\hline \multirow{2}{*}{\begin{tabular}{|c|} 
Total Reserve $=\$ 4$ \\
Game
\end{tabular}} & \multicolumn{5}{|c|}{ Auctions Starting on $3 / 11 / 2002$} & \multicolumn{5}{|c|}{ Auctions Starting on $3 / 12 / 2002$} \\
\hline & Treatment & Revenues & (\# bids, \# bidders) & high bid time & last bid time & Treatment & Revenues & (\# bids, \# bidders) & high bid time & last bid time \\
\hline Halo & B & $\$ 41.24$ & $(11,9)$ & d7 h23 & same & A & 34.05 & $(13,9)$ & d7 h24 & d7 h24 \\
\hline Wreckless & A & \$ 44.01 & $(7,7)$ & d7h20 & same & B & 33.99 & $(12,7)$ & d6 h23 & d7 h17 \\
\hline Circus Maximus & A & $\$ 40.99$ & $(8,7)$ & last minutes & same & B & 39.99 & $(10,6)$ & d7 h04 & same \\
\hline Max Payne & B & $\$ 36.99$ & $(16,10)$ & last minutes & same & A & 36.01 & $(24,10)$ & last minutes & same \\
\hline Genma Onimusha & B & $\$ 32.99$ & $(14,11)$ & last minutes & same & A & $\$ \quad 41.00$ & $(17,8)$ & d7 h24 & same \\
\hline Project Gotham Racing & B & $\$ 38.12$ & $(11,8)$ & last minutes & same & A & 37.00 & $(13,6)$ & d7 h24 & same \\
\hline NBA $2 \mathrm{~K} 2$ & A & $\$ 42.12$ & $(20,10)$ & d7 h20 & d7 h23 & B & 42.99 & $(15,9)$ & d7 h12 & d7 h24 \\
\hline NFL 2K2 & A & $\$ 26.00$ & $(14,5)$ & d7 h23 & d7 h24 & B & 33.99 & $(9,9)$ & d7 h24 & d2 h13 \\
\hline NHL 2002 & B & $\$ 37.00$ & $(8,8)$ & d6 h21 & d7 h02 & A & 36.00 & $(10,8)$ & last minutes & same \\
\hline WWF Raw & $A$ & $\$ 33.99$ & $(13,8)$ & d7 h22 & same & B & 40.99 & $(21,11)$ & last minutes & same \\
\hline
\end{tabular}

High Reserve Treatments:

\begin{tabular}{|c|c|c|c|c|c|c|c|c|c|c|c|}
\hline \multirow{2}{*}{$\begin{array}{r}\text { Total Reserve }=\$ 8 \\
\text { Game }\end{array}$} & \multicolumn{5}{|c|}{ Auctions Starting on $3 / 19 / 2002$} & \multicolumn{6}{|c|}{ Auctions Starting on $3 / 20 / 2002$} \\
\hline & Treatment & Revenues & (\# bids, \# bidders) & high bid time & last bid time & Treatment & & venues & (\# bids, \# bidders) & high bid time & last bid time \\
\hline Halo & C & $\$ 40.01$ & $(10,8)$ & d7 h23 & same & $\mathrm{D}$ & $\$$ & 43.00 & $(14,10)$ & d7 h24 & same \\
\hline Wreckless & D & $\$ 36.00$ & $(10,7)$ & d7 h13 & same & C & $\$$ & 35.00 & $(11,6)$ & d7 h20 & same \\
\hline Circus Maximus & D & $\$ 42.53$ & $(13,10)$ & d7 h22 & same & C & $\$$ & 39.00 & $(8,7)$ & d7 h17 & same \\
\hline Max Payne & C & $\$ 37.50$ & $(27,8)$ & d7 h24 & d7 h24 & D & $\$$ & 42.00 & $(24,11)$ & last minutes & same \\
\hline Genma Onimusha & D & $\$ 37.00$ & $(13,8)$ & d7 h24 & same & C & $\$$ & 36.00 & $(18,11)$ & last minutes & same \\
\hline Project Gotham Racing & C & $\$ 35.02$ & $(13,7)$ & last minutes & same & D & $\$$ & 40.01 & $(12,10)$ & d7 h24 & same \\
\hline NBA $2 \mathrm{~K} 2$ & D & $\$ 45.00$ & $(15,10)$ & last minutes & same & C & $\$$ & 41.00 & $(26,7)$ & d7 h17 & same \\
\hline NFL 2K2 & C & $\$ 33.00$ & $(15,8)$ & last minutes & same & D & $\$$ & 40.10 & $(21,10)$ & d7 h24 & last minutes \\
\hline NHL 2002 & C & $\$ 36.00$ & $(16,12)$ & last minutes & same & D & $\$$ & 41.00 & $(18,14)$ & d7 h24 & last minutes \\
\hline WWF Raw & D & $\$ 44.00$ & $(27,11)$ & d7 h24 & d7 h24 & C & $\$$ & 37.00 & $(17,10)$ & d7 h24 & same \\
\hline
\end{tabular}

\begin{tabular}{|l|c|}
\hline (Opening Bid, Shipping Cost) & Treatment \\
\hline$(\$ 4,0)$ & $\mathrm{A}$ \\
$(\$ 0.01, \$ 3.99)$ & $\mathrm{B}$ \\
$(\$ 6, \$ 2)$ & $\mathrm{C}$ \\
$(\$ 2, \$ 6)$ & $\mathrm{D}$ \\
\hline
\end{tabular}

Comments:

bidding time $=$ day ( 1 to 7$)$, hour ( 1 to 24$)$

"same" in the "last bid time" column means the last bid was the high bid

"last minutes" = bid in the last 5 minutes 
Table 3. Revenues from Low Reserve Treatments

\begin{tabular}{|l|l|l|r|r|}
\hline & $\begin{array}{l}\text { Revenues } \\
\text { under } \\
\text { Treatment A }\end{array}$ & $\begin{array}{l}\text { Revenues } \\
\text { under }\end{array}$ & & \multicolumn{2}{l|}{$\begin{array}{l}\text { Percent } \\
\text { Treatment B }\end{array}$} & B - A & \multicolumn{1}{l|}{ Difference } \\
\hline Music & 5.50 & 7.24 & 1.74 & $32 \%$ \\
Ooops! I Did it Again & 6.50 & 7.74 & 1.24 & $19 \%$ \\
Serendipity & 8.50 & 10.49 & 1.99 & $23 \%$ \\
O Brother Where Art Thou? & 12.50 & 11.99 & -0.51 & $-4 \%$ \\
Greatest Hits - Tim McGraw & 11.00 & 15.99 & 4.99 & $45 \%$ \\
A Day Without Rain & 13.50 & 14.99 & 1.49 & $11 \%$ \\
Automatic for the People & 0.00 & 9.99 & 9.99 & \\
Everyday & 7.28 & 9.49 & 2.21 & $30 \%$ \\
Joshua Tree & 6.07 & 8.25 & 2.18 & $36 \%$ \\
Unplugged in New York & 4.50 & 5.24 & 0.74 & $16 \%$ \\
& & & & \\
Average & 7.54 & 10.14 & 2.61 & $35 \%$ \\
Average excluding unsold & 8.37 & 10.16 & 1.79 & $21 \%$ \\
\hline
\end{tabular}

\begin{tabular}{|l|l|r|r|r|}
\hline & $\begin{array}{l}\text { Revenues } \\
\text { under } \\
\text { Treatment A }\end{array}$ & $\begin{array}{l}\text { Revenues } \\
\text { under } \\
\text { Xreatment B }\end{array}$ & B - A & \multicolumn{2}{|l|}{$\begin{array}{l}\text { Percent } \\
\text { Difference }\end{array}$} \\
\hline Halo Game Title & 34.05 & 41.24 & 7.19 & $21 \%$ \\
Wreckless & 44.01 & 33.99 & -10.02 & $-23 \%$ \\
Circus Maximus & 40.99 & 39.99 & -1.00 & $-2 \%$ \\
Max Payne & 36.01 & 36.99 & 0.98 & $3 \%$ \\
Genma Onimusha & 41.00 & 32.99 & -8.01 & $-20 \%$ \\
Project Gotham Racing & 37.00 & 38.12 & 1.12 & $3 \%$ \\
NBA 2K2 & 42.12 & 42.99 & 0.87 & $2 \%$ \\
NFL 2K2 & 26.00 & 33.99 & 7.99 & $31 \%$ \\
NHL 2002 & 36.00 & 37.00 & 1.00 & $3 \%$ \\
WWF Raw & 33.99 & 40.99 & 7.00 & $21 \%$ \\
& & & & \\
Average & 37.12 & 37.83 & 0.71 & $2 \%$ \\
\hline
\end{tabular}


Table 4. Revenues from High Reserve Treatments

\begin{tabular}{|l|l|l|l|l|}
\hline & $\begin{array}{l}\text { Revenues } \\
\text { under } \\
\text { Treatment C }\end{array}$ & $\begin{array}{l}\text { Revenues } \\
\text { under } \\
\text { Treatment D }\end{array}$ & D - C & \multicolumn{2}{l|}{$\begin{array}{l}\text { Percent } \\
\text { Difference }\end{array}$} \\
\hline Music & 9.00 & 8.00 & -1.00 & $-11 \%$ \\
Ooops! I Did it Again & $\mathbf{0 . 0 0}$ & $\mathbf{0 . 0 0}$ & 0.00 & \\
Serendipity & 12.50 & 13.50 & 1.00 & $8 \%$ \\
O Brother Where Art Thou? & 11.52 & 11.00 & -0.52 & $-5 \%$ \\
Greatest Hits - Tim McGraw & 18.00 & 17.00 & -1.00 & $-6 \%$ \\
A Day Without Rain & 15.50 & 16.00 & 0.50 & $3 \%$ \\
Automatic for the People & $\mathbf{0 . 0 0}$ & $\mathbf{0 . 0 0}$ & 0.00 & \\
Everyday & 10.50 & 13.50 & 3.00 & $29 \%$ \\
Joshua Tree & 8.00 & 11.10 & 3.10 & $39 \%$ \\
Unplugged in New York & 8.00 & $\mathbf{0 . 0 0}$ & -8.00 & $-100 \%$ \\
& & & & $-3 \%$ \\
Average & 9.30 & 9.01 & -0.29 & $6 \%$ \\
Average excluding unsold & 12.15 & 12.87 & 0.73 & \\
\hline
\end{tabular}

\begin{tabular}{|l|l|l|l|l|}
\hline & $\begin{array}{l}\text { Revenues } \\
\text { under } \\
\text { Treatment C }\end{array}$ & $\begin{array}{l}\text { Revenues } \\
\text { under } \\
\text { Treatment D }\end{array}$ & D - C & \multicolumn{2}{|l|}{$\begin{array}{l}\text { Percent } \\
\text { Difference }\end{array}$} \\
\hline Halo & 40.01 & 43.00 & 2.99 & $7 \%$ \\
Wreckless & 35.00 & 36.00 & 1.00 & $3 \%$ \\
Circus Maximus & 39.00 & 42.53 & 3.53 & $9 \%$ \\
Max Payne & 37.50 & 42.00 & 4.50 & $12 \%$ \\
Genma Onimusha & 36.00 & 37.00 & 1.00 & $3 \%$ \\
Project Gotham Racing & 35.02 & 40.01 & 4.99 & $14 \%$ \\
NBA 2K2 & 41.00 & 45.00 & 4.00 & $10 \%$ \\
NFL 2K2 & 33.00 & 40.10 & 7.10 & $22 \%$ \\
NHL 2002 & 36.00 & 41.00 & 5.00 & $14 \%$ \\
WWF Raw & 37.00 & 44.00 & 7.00 & $19 \%$ \\
& & & & \\
Average & 36.95 & 41.06 & 4.11 & $11 \%$ \\
\hline
\end{tabular}


Table 5. Effects on Revenues of Changes in Reserve Price - A vs C

\begin{tabular}{|l|l|l|lr|}
\hline & $\begin{array}{l}\text { Revenues } \\
\text { under } \\
\text { Treatment A }\end{array}$ & $\begin{array}{l}\text { Revenues } \\
\text { under } \\
\text { Treatment C }\end{array}$ & C - A & \multicolumn{2}{|l|}{$\begin{array}{l}\text { Percent } \\
\text { Difference }\end{array}$} \\
\hline CD Title & 5.50 & 9.00 & 3.50 & $64 \%$ \\
Music & 6.50 & $\mathbf{0 . 0 0}$ & -6.50 & $-100 \%$ \\
Serendipity I Did it Again & 8.50 & 12.50 & 4.00 & $47 \%$ \\
O Brother Where Art Thou? & 12.50 & 11.52 & -0.98 & $-8 \%$ \\
Greatest Hits - Tim McGraw & 11.00 & 18.00 & 7.00 & $64 \%$ \\
A Day Without Rain & 13.50 & 15.50 & 2.00 & $15 \%$ \\
Automatic for the People & $\mathbf{0 . 0 0}$ & $\mathbf{0 . 0 0}$ & 0.00 & \\
Everyday & 7.28 & 10.50 & 3.22 & $44 \%$ \\
Joshua Tree & 6.07 & 8.00 & 1.93 & $32 \%$ \\
Unplugged in New York & 4.50 & 8.00 & 3.50 & $78 \%$ \\
& & & & \\
Average & 7.54 & 9.30 & 1.77 & $23 \%$ \\
Average excluding unsold & 8.61 & 11.63 & 3.02 & $35 \%$ \\
\hline
\end{tabular}

\begin{tabular}{|l|l|l|r|r|}
\hline & $\begin{array}{l}\text { Revenues } \\
\text { under } \\
\text { Treatment A }\end{array}$ & $\begin{array}{l}\text { Revenues } \\
\text { under } \\
\text { Treatment C }\end{array}$ & C - A & \multicolumn{2}{l|}{$\begin{array}{l}\text { Percent } \\
\text { Difference }\end{array}$} \\
\hline Halo & 34.05 & 40.01 & 5.96 & $18 \%$ \\
Wreckless & 44.01 & 35.00 & -9.01 & $-20 \%$ \\
Circus Maximus & 40.99 & 39.00 & -1.99 & $-5 \%$ \\
Max Payne & 36.01 & 37.50 & 1.49 & $4 \%$ \\
Genma Onimusha & 41.00 & 36.00 & -5.00 & $-12 \%$ \\
Project Gotham Racing & 37.00 & 35.02 & -1.98 & $-5 \%$ \\
NBA 2K2 & 42.12 & 41.00 & -1.12 & $-3 \%$ \\
NFL 2K2 & 26.00 & 33.00 & 7.00 & $27 \%$ \\
NHL 2002 & 36.00 & 36.00 & 0.00 & $0 \%$ \\
WWF Raw & 33.99 & 37.00 & 3.01 & $9 \%$ \\
Average & 37.12 & 36.95 & -0.16 & $0 \%$ \\
\hline
\end{tabular}


Table 6. Effects on Revenues of Changes in Reserve Price - B vs D

\begin{tabular}{|l|r|r|r|r|}
\hline & $\begin{array}{l}\text { Revenues } \\
\text { under } \\
\text { Treatment B }\end{array}$ & $\begin{array}{l}\text { Revenues } \\
\text { under } \\
\text { Treatment D }\end{array}$ & D - B & \multicolumn{2}{l|}{$\begin{array}{l}\text { Percent } \\
\text { Difference }\end{array}$} \\
\hline Music & 7.24 & 8.00 & 0.76 & $10 \%$ \\
Ooops! I Did it Again & 7.74 & $\mathbf{0 . 0 0}$ & -7.74 & $-100 \%$ \\
Serendipity & 10.49 & 13.50 & 3.01 & $29 \%$ \\
O Brother Where Art Thou? & 11.99 & 11.00 & -0.99 & $-8 \%$ \\
Greatest Hits - Tim McGraw & 15.99 & 17.00 & 1.01 & $6 \%$ \\
A Day Without Rain & 14.99 & 16.00 & 1.01 & $7 \%$ \\
Automatic for the People & 9.99 & $\mathbf{0 . 0 0}$ & -9.99 & $-100 \%$ \\
Everyday & 9.49 & 13.50 & 4.01 & $42 \%$ \\
Joshua Tree & 8.25 & 11.10 & 2.85 & $35 \%$ \\
Unplugged in New York & 5.24 & $\mathbf{0 . 0 0}$ & -5.24 & $-100 \%$ \\
& & & & \\
Average & 10.14 & 9.01 & -1.13 & $-11 \%$ \\
Average excluding unsold & 11.21 & 12.87 & 1.67 & $15 \%$ \\
\hline
\end{tabular}

\begin{tabular}{|l|l|l|l|l|}
\hline & $\begin{array}{l}\text { Revenues } \\
\text { under } \\
\text { Treatment B }\end{array}$ & $\begin{array}{l}\text { Revenues } \\
\text { under } \\
\text { Treatment D }\end{array}$ & D - B & \multicolumn{2}{|l|}{$\begin{array}{l}\text { Percent } \\
\text { Difference }\end{array}$} \\
\hline Halo Title & 41.24 & 43.00 & 1.76 & $4 \%$ \\
Wreckless & 33.99 & 36.00 & 2.01 & $6 \%$ \\
Circus Maximus & 39.99 & 42.53 & 2.54 & $6 \%$ \\
Max Payne & 36.99 & 42.00 & 5.01 & $14 \%$ \\
Genma Onimusha & 32.99 & 37.00 & 4.01 & $12 \%$ \\
Project Gotham Racing & 38.12 & 40.01 & 1.89 & $5 \%$ \\
NBA 2K2 & 42.99 & 45.00 & 2.01 & $5 \%$ \\
NFL 2K2 & 33.99 & 40.10 & 6.11 & $18 \%$ \\
NHL 2002 & 37.00 & 41.00 & 4.00 & $11 \%$ \\
WWF Raw & 40.99 & 44.00 & 3.01 & $7 \%$ \\
Average & 37.83 & 41.06 & 3.24 & $9 \%$ \\
\hline
\end{tabular}


Table 7. Bidder behavior in CD Auctions

\begin{tabular}{|c|c|c|c|c|c|c|c|c|c|c|c|c|c|c|}
\hline Total Reserve $=\$ 4$ & \multicolumn{7}{|c|}{ Treatment A } & \multicolumn{7}{|c|}{ Treatment B } \\
\hline CD & \# of Bidders & Nibblers & Returners & Both & Snipers & Ret Snipers & \begin{tabular}{|l|} 
Winner Ret \\
\end{tabular} & \# of Bidders & Nibblers & Returners & Both & Snipers & Ret Snipers & \begin{tabular}{|l|} 
Winner Ret \\
\end{tabular} \\
\hline Music & 2 & 0 & 2 & 0 & 1 & 1 & $\mathrm{Y}$ & 4 & 1 & 1 & 1 & 2 & 0 & $\mathrm{~N}$ \\
\hline Ooops! I Did it Again & 3 & 0 & 0 & 0 & 1 & 0 & $\mathrm{~N}$ & 4 & 1 & 1 & 0 & 1 & 0 & $\mathrm{Y}$ \\
\hline Serendipity & 4 & 1 & 0 & 0 & 1 & 0 & $\mathrm{~N}$ & 4 & 1 & 1 & 1 & 1 & 1 & $\mathrm{Y}$ \\
\hline O Brother Where Art Thou? & 7 & 0 & 0 & 0 & 0 & 0 & $\mathrm{~N}$ & 4 & 2 & 1 & 1 & 0 & 0 & $\mathrm{~N}$ \\
\hline Tim McGraw & 8 & 1 & 1 & 0 & 1 & 0 & $\mathrm{~N}$ & 8 & 2 & 0 & 0 & 1 & 0 & $\mathrm{~N}$ \\
\hline A Day Without Rain & 6 & 1 & 0 & 0 & 0 & 0 & $\mathrm{~N}$ & 6 & 2 & 1 & 0 & 0 & 0 & $\mathrm{Y}$ \\
\hline Automatic for the People & 0 & -1 & - & - & - & - & - & 3 & 0 & 1 & 0 & 1 & 1 & $\mathrm{Y}$ \\
\hline Everyday & 3 & 0 & 0 & 0 & 0 & 0 & $\mathrm{~N}$ & 7 & 1 & 0 & 0 & 1 & 0 & $\mathrm{~N}$ \\
\hline Joshua Tree & 3 & 0 & 0 & 0 & 1 & 0 & $\mathrm{~N}$ & 3 & 1 & 0 & 0 & 1 & 0 & $\mathrm{~N}$ \\
\hline Overall Outcomes & 3.90 & 0.33 & 0.33 & - & 0.56 & 0.11 & 1 of 9 & 4.50 & 1.10 & 0.60 & 0.30 & 0.80 & 0.20 & 4 of 10 \\
\hline
\end{tabular}

\begin{tabular}{|c|c|c|c|c|c|c|c|c|c|c|c|c|c|c|}
\hline Total Reserve $=\$ 8$ & \multicolumn{7}{|c|}{ Treatment C } & \multicolumn{7}{|c|}{ Treatment D } \\
\hline CD & \# of Bidders & Nibblers & Returners & Both & Snipers & Ret Snipers & \begin{tabular}{|l|} 
Winner Ret \\
\end{tabular} & \# of Bidders & Nibblers & Returners & Both & Snipers & Ret Snipers & \begin{tabular}{|l|} 
Winner Ret \\
\end{tabular} \\
\hline Music & 3 & 0 & 0 & 0 & 1 & 0 & $\mathrm{~N}$ & 1 & 0 & 0 & 0 & 0 & 0 & $\mathrm{~N}$ \\
\hline Ooops! I Did it Again & 0 & 1 & - & - & 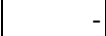 & - & . & 0 & - & 1 & - & & & \\
\hline Serendipity & 4 & 1 & 0 & 0 & 0 & 0 & $\mathrm{~N}$ & 4 & 1 & 0 & 0 & 0 & 0 & $\mathrm{~N}$ \\
\hline O Brother Where Art Thou? & 5 & 0 & 0 & 0 & 1 & 0 & $\mathrm{~N}$ & 5 & 1 & 0 & 0 & 0 & 0 & $\mathrm{~N}$ \\
\hline Tim McGraw & 3 & 3 & 1 & 1 & 0 & 0 & $\mathrm{Y}$ & 7 & 2 & 2 & 1 & 0 & 0 & $\mathrm{~N}$ \\
\hline A Day Without Rain & 7 & 2 & 2 & 0 & 2 & 0 & $\mathrm{~N}$ & 5 & 1 & 1 & 1 & 0 & 0 & $\mathrm{~N}$ \\
\hline Automatic for the People & 0 & - & & - & & - & - & 0 & - & - & - & - & - & \\
\hline Everyday & 4 & 1 & 1 & 1 & 0 & 0 & $\mathrm{Y}$ & 4 & 1 & 0 & 0 & 0 & 0 & $\mathrm{~N}$ \\
\hline Joshua Tree & 1 & 0 & 0 & 0 & 0 & 0 & $\mathrm{~N}$ & 4 & 2 & 0 & 0 & 1 & 0 & $\mathrm{~N}$ \\
\hline Overall Outcomes & 2.80 & 0.88 & 0.50 & 0.25 & 0.50 & - & 2 of 8 & 3.00 & 1.14 & 0.43 & 0.29 & 0.14 & - & 0 of 7 \\
\hline
\end{tabular}

Returners $=$ Number of bidders who were displaced as high bidder and made subsequent bid

Nibblers $=$ Number of bidders who made subsequent bid after initial bid revealed he was not high bidder

Both $=$ Number of bidders who were both nibbler and returner

Snipers $=$ Number of bidders who placed a bid in the last hour of the auction

Ret Snipers $=$ Number of bidders placing a bid in the last hour of the auction who had previously placed a bid

Winner Ret $=$ Yes if the winning bidder was previously displaced as high bidder 
Table 8. Bidder behavior in Xbox Auctions

\begin{tabular}{|c|c|c|c|c|c|c|c|c|c|c|c|c|c|c|}
\hline Total Reserve $=\$ 4$ & \multicolumn{7}{|c|}{ Treatment A } & \multicolumn{7}{|c|}{ Treatment B } \\
\hline Xbox Game & \# of Bidders & Nibblers & Returners & Both & Snipers & Ret Snipers & Winner Ret & \# of Bidders & Nibblers & Returners & Both & Snipers & Ret Snipers & \begin{tabular}{|l|} 
Winner Ret \\
\end{tabular} \\
\hline Halo & 9 & 1 & 0 & 0 & 2 & 0 & $\mathrm{~N}$ & 9 & 2 & 0 & 0 & 0 & 0 & $\mathrm{~N}$ \\
\hline Wreckless & 7 & 0 & 0 & 0 & 0 & 0 & $\mathrm{~N}$ & 7 & 2 & 2 & 1 & 0 & 0 & $\mathrm{~N}$ \\
\hline Circus Maximus & 7 & 1 & 0 & 0 & 1 & 0 & $\mathrm{~N}$ & 6 & 3 & 1 & 1 & 0 & 0 & $\mathrm{~N}$ \\
\hline Max Payne & 10 & 2 & 2 & 1 & 1 & 0 & $\mathrm{~N}$ & 10 & 2 & 2 & 0 & 2 & 0 & $\mathrm{~N}$ \\
\hline Genma Onimusha & 8 & 4 & 2 & 2 & 2 & 2 & $\mathrm{Y}$ & 11 & 2 & 1 & 1 & 3 & 0 & $\mathrm{~N}$ \\
\hline Project Gotham Racing & 6 & 2 & 2 & 1 & 1 & 0 & $\mathrm{~N}$ & 8 & 1 & 1 & 1 & 3 & 0 & $\mathrm{~N}$ \\
\hline NBA 2K2 & 10 & 2 & 2 & 1 & 0 & 0 & $\mathrm{~N}$ & 9 & 1 & 2 & 0 & 1 & 1 & $\mathrm{~N}$ \\
\hline NFL 2K2 & 5 & 1 & 2 & 0 & 1 & 1 & $\mathrm{Y}$ & 9 & 0 & 0 & 0 & 0 & 1 & $\mathrm{~N}$ \\
\hline NHL 2002 & 8 & 1 & 1 & 0 & 2 & 0 & $\mathrm{~N}$ & 8 & 0 & 0 & 0 & 0 & 0 & $\mathrm{~N}$ \\
\hline Overall Outcomes & 7.80 & 1.60 & 1.20 & 0.60 & 1.00 & 0.30 & 2 of 10 & 8.80 & 1.70 & 1.00 & 0.50 & 1.20 & 0.20 & 0 of 10 \\
\hline
\end{tabular}

\begin{tabular}{|c|c|c|c|c|c|c|c|c|c|c|c|c|c|c|}
\hline Total Reserve $=\$ 8$ & \multicolumn{7}{|c|}{ Treatment C } & \multicolumn{7}{|c|}{ Treatment D } \\
\hline Xbox Game & \# of Bidders & Nibblers & Returners & Both & Snipers & Ret Snipers & Winner Ret & \# of Bidders & Nibblers & Returners & Both & Snipers & Ret Snipers & \begin{tabular}{|l|} 
Winner Ret \\
\end{tabular} \\
\hline Halo & 8 & 1 & 1 & 0 & 0 & 0 & $\mathrm{~N}$ & 10 & 2 & 2 & 0 & 2 & 1 & $\mathrm{Y}$ \\
\hline Wreckless & 6 & 2 & 1 & 1 & 0 & 0 & $\mathrm{~N}$ & 7 & 1 & 1 & 0 & 0 & 0 & $\mathrm{Y}$ \\
\hline Circus Maximus & 7 & 0 & 0 & 0 & 0 & 0 & $\mathrm{~N}$ & 10 & 2 & 0 & 0 & 0 & 0 & $\mathrm{~N}$ \\
\hline Max Payne & 8 & 2 & 1 & 1 & 2 & 1 & $\mathrm{~N}$ & 11 & 3 & 2 & 1 & 2 & 0 & $\mathrm{~N}$ \\
\hline Genma Onimusha & 11 & 1 & 1 & 1 & 1 & 0 & $\mathrm{~N}$ & 8 & 1 & 1 & 0 & 1 & 0 & $\mathrm{~N}$ \\
\hline Project Gotham Racing & 7 & 0 & 4 & 0 & 3 & 1 & $\mathrm{Y}$ & 10 & 0 & 2 & 0 & 2 & 1 & $\mathrm{Y}$ \\
\hline NBA 2K2 & 7 & 3 & 2 & 1 & 0 & 0 & $\mathrm{Y}$ & 10 & 3 & 1 & 1 & 3 & 1 & $\mathrm{~N}$ \\
\hline NFL 2K2 & 8 & 3 & 1 & 0 & 1 & 0 & $\mathrm{~N}$ & 10 & 3 & 4 & 3 & 2 & 2 & $\mathrm{Y}$ \\
\hline NHL 2002 & 12 & 2 & 0 & 0 & 1 & 0 & $\mathrm{~N}$ & 14 & 3 & 0 & 0 & 3 & 0 & $\mathrm{~N}$ \\
\hline Overall Outcomes & 8.40 & 1.60 & 1.30 & 0.50 & 1.10 & 0.30 & 3 of 10 & 10.10 & 2.30 & 1.80 & 0.90 & 1.80 & 0.70 & 5 of 10 \\
\hline
\end{tabular}

Returners $=$ Number of bidders who were displaced as high bidder and made subsequent bid

Nibblers $=$ Number of bidders who made subsequent bid after initial bid revealed he was not high bidder

Both $=$ Number of bidders who were both nibbler and returner

Snipers $=$ Number of bidders who placed a bid in the last hour of the auction

Ret Snipers $=$ Number of bidders placing a bid in the last hour of the auction who had previously placed a bid

Winner Ret $=$ Yes if the winning bidder was previously displaced as high bidder 
Table 9. Revenues and Timing of First Bid

\begin{tabular}{|c|c|c|c|c|}
\hline & \multicolumn{2}{|c|}{ Total Reserve $=\$ 4$} & \multicolumn{2}{|c|}{ Total Reserve $=\$ 8$} \\
\hline CD & Earlier First Arrival & Higher Revenue & Earlier First Arrival & Higher Revenue \\
\hline Music & $\mathrm{B}$ & $\mathrm{B}$ & $\mathrm{C}$ & $\mathrm{C}$ \\
\hline Ooops! I Did it Again & $\mathrm{B}$ & $\mathrm{B}$ & - & - \\
\hline Serendipity & B & B & $\mathrm{D}$ & $\mathrm{D}$ \\
\hline O Brother Where Art Thou? & $\mathrm{B}$ & $A$ & $\mathrm{D}$ & $\mathrm{C}$ \\
\hline Tim McGraw & A & $B$ & $\mathrm{C}$ & $\mathrm{C}$ \\
\hline A Day Without Rain & $B$ & $B$ & $\mathrm{C}$ & $\mathrm{D}$ \\
\hline Automatic for the People & $B$ & $B$ & - & - \\
\hline Everyday & $B$ & $B$ & $\mathrm{D}$ & $\mathrm{D}$ \\
\hline Joshua Tree & $A$ & $B$ & $\mathrm{C}$ & $\mathrm{D}$ \\
\hline Unplugged in New York & $\mathrm{B}$ & $\mathrm{B}$ & $\mathrm{C}$ & $\mathrm{C}$ \\
\hline earlier bid => higher revenue & & 7 of 10 & & 5 of 8 \\
\hline
\end{tabular}

\begin{tabular}{|c|c|c|c|c|}
\hline & \multicolumn{2}{|c|}{ Total Reserve $=\$ 4$} & \multicolumn{2}{|c|}{ Total Reserve $=\$ 8$} \\
\hline Game & Earlier First Arrival & Higher Revenue & Earlier First Arrival & Higher Revenue \\
\hline Halo & $\mathrm{B}$ & $\mathrm{B}$ & $\bar{D}$ & $\bar{D}$ \\
\hline Wreckless & $\mathrm{B}$ & $A$ & $\mathrm{D}$ & $\mathrm{D}$ \\
\hline Circus Maximus & $\mathrm{B}$ & $A$ & $\mathrm{D}$ & $\mathrm{D}$ \\
\hline Max Payne & $\mathrm{B}$ & $\mathrm{B}$ & $\mathrm{D}$ & $\mathrm{D}$ \\
\hline Genma Onimusha & $\mathrm{B}$ & $A$ & $\mathrm{D}$ & $\mathrm{D}$ \\
\hline Project Gotham Racing & $\mathrm{B}$ & $B$ & $\mathrm{D}$ & $\mathrm{D}$ \\
\hline NBA $2 \mathrm{~K} 2$ & $\mathrm{~B}$ & $\mathrm{~B}$ & $\mathrm{D}$ & $\mathrm{D}$ \\
\hline NFL 2K2 & $\mathrm{B}$ & $B$ & $\mathrm{D}$ & $\mathrm{D}$ \\
\hline NHL 2002 & $\mathrm{~B}$ & $B$ & $\mathrm{D}$ & $\mathrm{D}$ \\
\hline WWF Raw & $\mathrm{B}$ & $\mathrm{B}$ & $\mathrm{D}$ & $\mathrm{D}$ \\
\hline earlier bid => higher revenue & & 7 of 10 & & 10 of 10 \\
\hline
\end{tabular}


Table 10. Differences in Revenue Differences Under Various Treatments

\begin{tabular}{|l|r|r|}
\hline & Test Statistic & DF \\
\hline Difference-in-Differences ((B-A)-(D-C)) for CD & 2.319 & -05, DF) \\
Difference-in-Differences ((B-A)-(D-C)) for Xbox & -2.409 & 1.833 \\
Difference in Xbox and CD Revenue Differences for Low Reserve (B-A) & -0.891 & 9 \\
Difference in Xbox and CD Revenue Differences for High Reserve (D-C) & 3.733 & 13 \\
\end{tabular}

